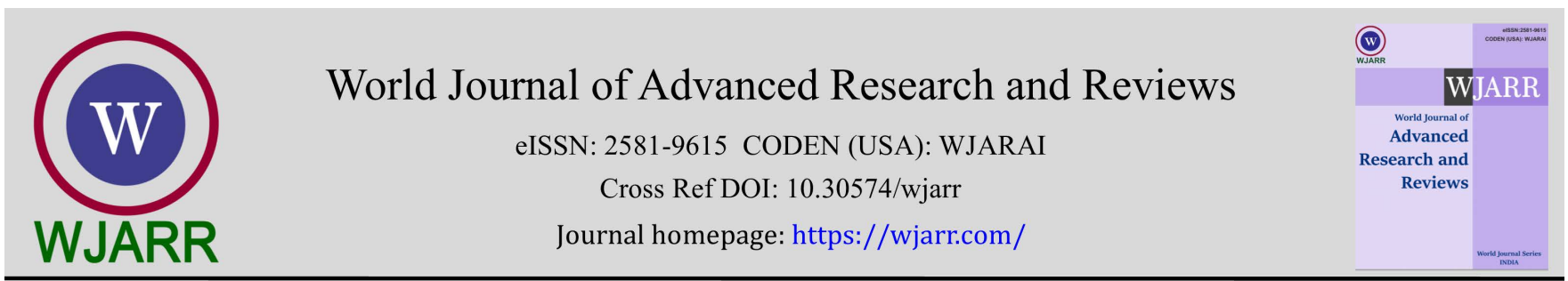

(RESEARCH ARTiClE)

\title{
The Sunn [Eurygaster spp. (Hemiptera: Scutelleridae)] damage in wheat and the effect of seed amount used on yield by fuzzy logic method
}

\author{
Mustafa Ilcin $1,{ }^{*}$ and Senol Celik ${ }^{2}$ \\ ${ }^{1}$ Department of Entomology, Plant of Protection, Faculty of Agriculture, Bingol University, Bingol, Turkey. \\ ${ }^{2}$ Department of Animal Science, Biometry and Genetic, Faculty of Agriculture, Bingol University, Bingol, Turkey.
}

World Journal of Advanced Research and Reviews, 2021, 11(01), 239-246

Publication history: Received on 27 March 2021; revised on 29 April 2021; accepted on 01 May 2021

Article DOI: https://doi.org/10.30574/wjarr.2021.11.1.0193

\begin{abstract}
Sunn pest (Eurygaster spp.) is a highly harmful insect species for Wheatgrass. Especially with the emphasis it makes in herbal products, it causes the wheat to lose both its bread and pasta qualities. This study presents an example of a model that approximates the wheat yield in the irrigated field in Batman province according to the criteria selected through fuzzy logic. In the modelling, firstly the parameters affecting the wheat yield were determined and input and output variables were defined. In the next step, the membership functions are determined by doing the blurring process. The triangular membership function has been selected for the membership function. Later, fuzzy rule base was determined and fuzzy rules were formed. In the next step, the fuzzy inference mechanism was created. For the rinsing process, the "weight average" method was used. In the study, fuzzy logic toolbox was used in Matlab and the results obtained were seen to be useful in determining wheat yield per decare.
\end{abstract}

Keywords: Wheat; Sunn pest; Fuzzy logic; Membership

\section{Introduction}

Wheat, Triticum aestivum L. (Poales: Poaceae) is a plant whose homeland in Anatolia. According to the data of the United Nations Food and Agriculture Organization (FAO), world wheat production was approximately 734 million tons in 2018, and the country that took first place in wheat production is the People's Republic of China. With Turkey in world wheat production is about 20 million tons of annual production ranks $11^{\text {th }}$ [1].

There are 15 types of sunn pests in the world that belong to the Eurygaster genus. 7 of these species are also found in our country. These species are Eurygaster integriceps Put, E. maura L., E. austriacus Schrk, E.dilaticollis Dohrn, E.hottentota F., E.schreiberi Mont, and E.testudinaria Geoff. Eurygaster integriceps Put. (Sunn), Eurygaster maura L. (European Sunn) and Eurygaster austriaca Schrk. The (Flat-bodied Sunflower) species are economically important for our country and are widely found in our regions. Other species have no economic significance [2].

The sunn species are generally earth-coloured, sometimes completely black, sometimes reddish, sometimes off-white, and sometimes with a piebald pattern that is a mixture of these colours. The body is flat, the upper part is slightly bumping and the top view is oval. They secrete stench as a family feature to which they are attached. Sunn gives offspring once a year. The life of adults is divided into two periods as active and passive. The first is the period from July to November following the harvest and is called the summer period. The second is the period from November to April and is defined as the wintering period. The degree and type of damage of the sun; varies depending on the intensity of the pest in question, its biological periods, the type and phenological condition of the product, and climatic conditions (temperature and precipitation). Both nymphs and adults cause damage by inserting and sucking the grasses in various

\footnotetext{
${ }^{*}$ Corresponding author: Mustafa Ilcin

Department of Entomology, Plant of Protection, Faculty of Agriculture, Bingol University, Bingol, Turkey.
}

Copyright (C) 2021 Author(s) retain the copyright of this article. This article is published under the terms of the Creative Commons Attribution Liscense 4.0. 
phenological periods with their hoses. After wintering, the overwintered adults migrating to the cereal fields in the plains in the spring absorb the wheat and some other wheat stalks that are still in the tailoring period and take their juice. The absorbed stems turn yellow and dry over time. Therefore, they do not bind spike. This form of damage is called Wolf's throat. As the plants develop over time, the overwintered adults continue to feed in the upper parts of the plants; while the spikes are still in the leaf sheath, they feed on the stems during the flowering period and while the grain is tying, thus preventing the spikes from acquiring a whitish colour, drying and thus binding the grain. The damage of overwintered adults in this way is called white-spike [3].

In his experiments with E. maura overwintered adults in the Central Anatolia region in cages; It has been revealed that an average of 16 overwintered adolescents per square meter can cause white-spike damage at rates varying between $0.95 \%$ and $2.49 \%$ on average, depending on the years [4]. In this study, it is aimed to determine the yield of wheat per decare by using fuzzy logic, taking into consideration the sunn pest and the seed used.

\section{Material and methods}

\subsection{Material}

The material of this study in Batman Province, Turkey amount of wheat they produce belonging to farmers producing wheat, wheat yield, EMG in harmful quantities of seed and the water they use is the rate of their struggle. Between the years of 2014-2017, the generally used seed amount in Batman is 22-24 kg, the yield per decare in the dry area is 300$450 \mathrm{~kg}$, the yield per decare in the irrigated area is $550-750 \mathrm{~kg}$, the wheat cultivation area is $593500-779058$ decares, the survey area 341000- The average emd rate (\%) in the area of 381,650 decares and the area under struggle has been recorded as between 0.4-0.78 [5].

\subsection{Method}

The theory of fuzzy logic was first developed by Dr. Lotfi Zadeh in the 1960s. It is based on the human way of thinking in problem-solving. It is closer to the way people brain work. Fuzzy logic includes the various states of truth which were improved by Lukasiewicz in the 1930s. When the data are aggregated and formed several partial truths, it is aggregated further into higher truths which in turn cause certain further results [6].

Zadeh presented the concept of "Fuzzy Sets", which started the fuzzy set theory, for the first time, object sets whose borders are not defined sharply. The fuzzy set theory goals to model the imprecise information that exists in the real world. It is not easy to precisely and accurately model many problems in practice, as they are extremely complex and poorly designed [7].

The way to calculate the triangular linguistics variable in fuzzy logic is displayed in follow [8].

$$
f(x, a, b, c)=\left\{\begin{array}{l}
\frac{x-a}{b-a}, a \leq x \leq b \\
\frac{c-x}{c-b}, b \leq x \leq c \\
0, x \leq c \text { or } x \leq a
\end{array}\right.
$$

In the determination of fuzzy logic-based wheat yield, the inputs, the amount of seed used and the Emd rate (\%) in the area of struggle, and the output wheat yield per decare were defined (Table 1). The system structure is presented in Figure 1.

Table 1 Input, output and membership functions

\begin{tabular}{|c|l|l|l|l|c|}
\hline & \multicolumn{1}{|c|}{ Variables } & \multicolumn{2}{c|}{ Values } & \multicolumn{3}{c|}{ Membership functions } \\
\hline \multirow{3}{*}{ Input } & Seed & $21-25 \mathrm{~kg}$ & Low & Medium & High \\
\cline { 2 - 6 } & Emd rate (\%) & $0.4-0.8$ & Low & Medium & High \\
\hline \multirow{2}{*}{ Output } & Yield & $550-750 \mathrm{~kg}$ & Low & Medium & High \\
\hline
\end{tabular}


Fuzzy sets and expressions were formed according to the data here. Fuzzy sets for each of the input data were formed in the low, medium and high ranges. The seed variable was defined in the range of $21-25 \mathrm{~kg}$, the Emd rate variable in the range of $0.4-0.8 \%$, and the yield per decare in the range of $550-750 \mathrm{~kg}$.

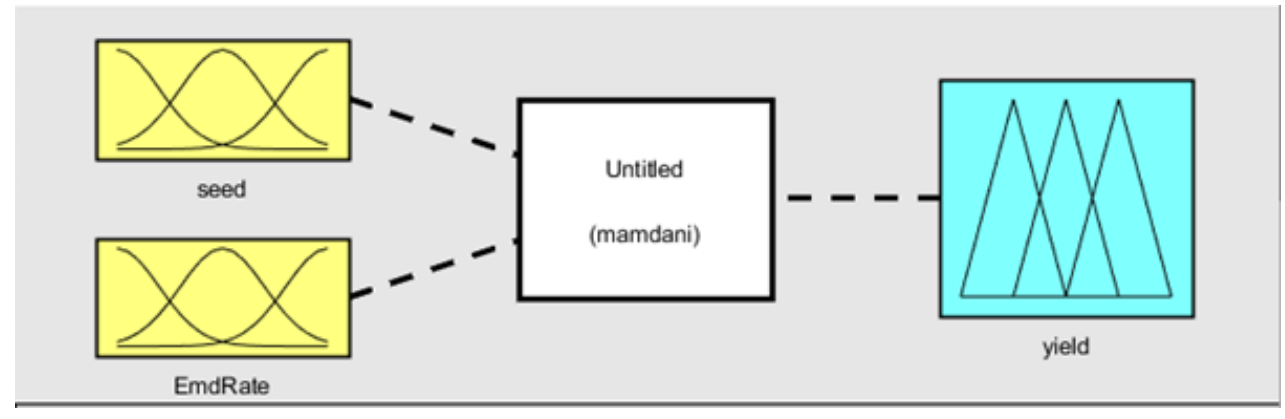

Figure 1 Fuzzy logic based wheat yield estimation

In the system, levels are defined according to value ranges in order to define membership functions. Three levels (low, medium, high) for seed input data, three levels (low, medium, high) for barn rate input data and three levels (low, medium, high) for yield output data per decare were also defined. Membership functions used in the system are shown in Figure 2.
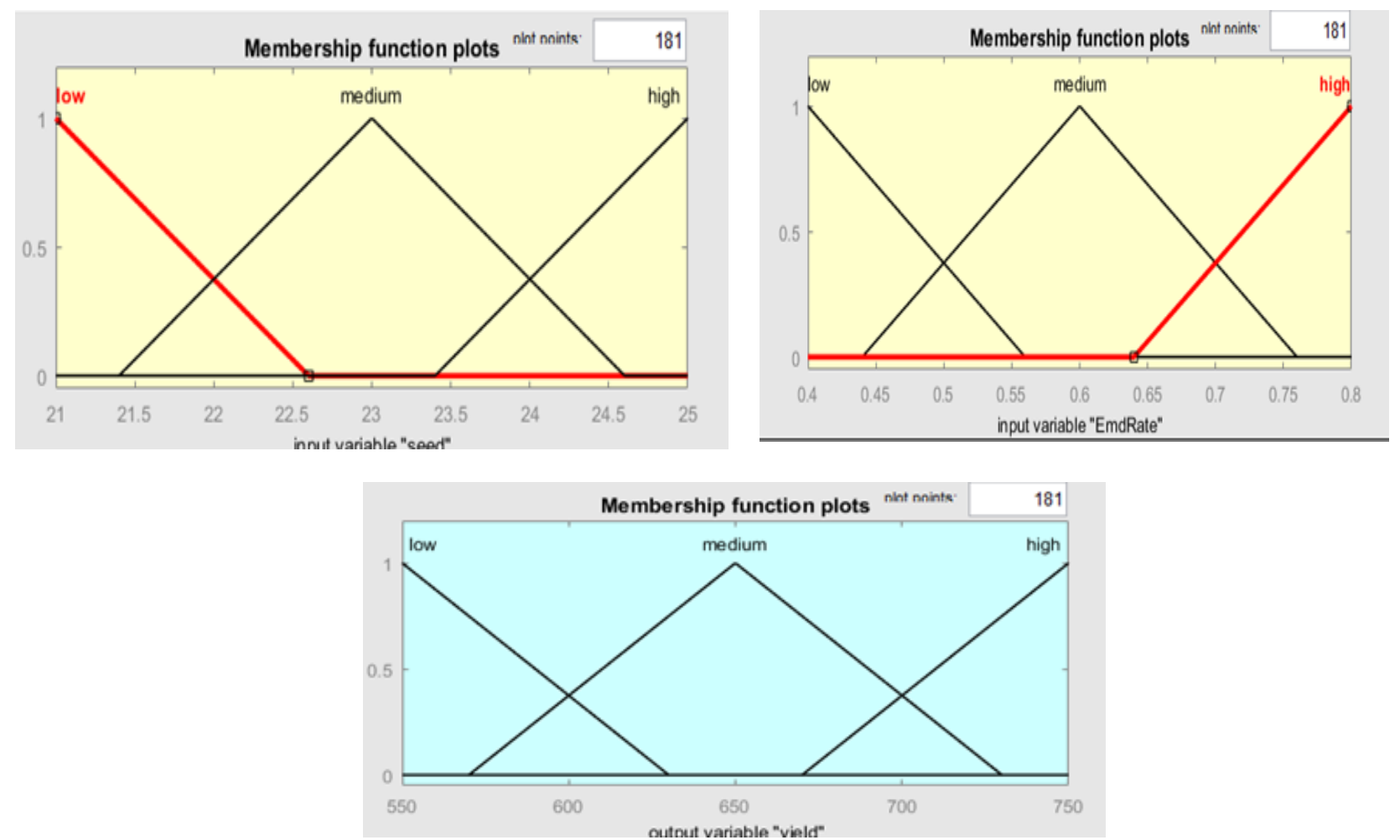

The analysis of fuzzy logic application was carried out using Matlab Fuzzy toolbox

Figure 2 Membership function plots

\section{Results and discussion}

In the fuzzy logic application, input and output variables are defined to determine the wheat yield per decare. The triangular membership function has been preferred for the membership function. While the input variables are the seed and the Emd rate, the output variable is the yield. In Figure 3, the parameters of the fuzzy model consisting of two input and one output parameter and the modelling of the system in the MATLAB R2016b program are shown. 


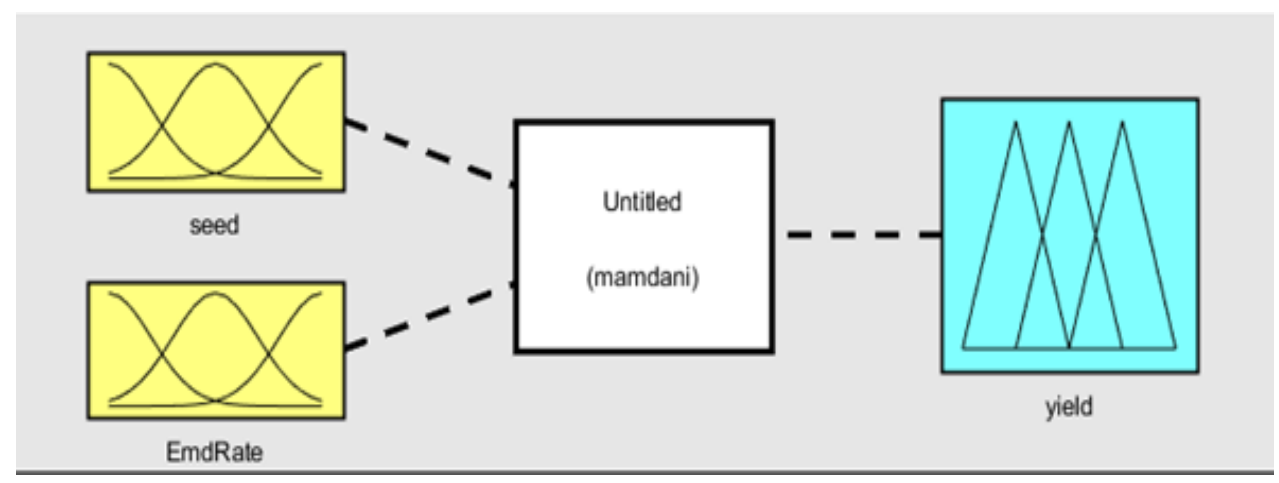

Figure 3 Matlab view of modelling

Graphical representation of "seed" input parameter in Matlab environment is given in Figure 4

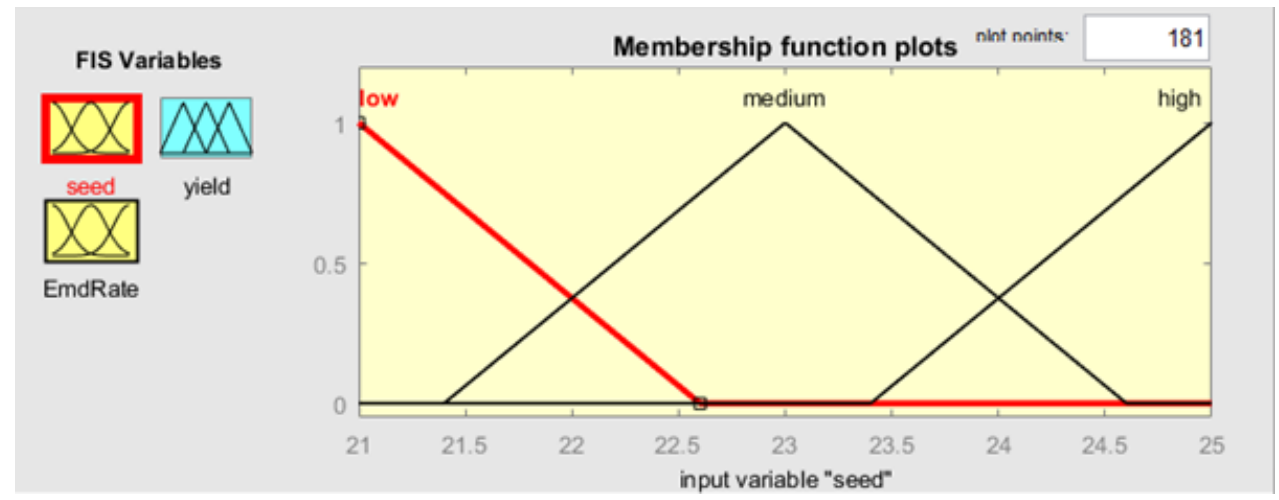

Figure 4 Seed input parameter membership functions

The graphical representation of the "emission rate" input parameter in Matlab environment is given in Figure 5.

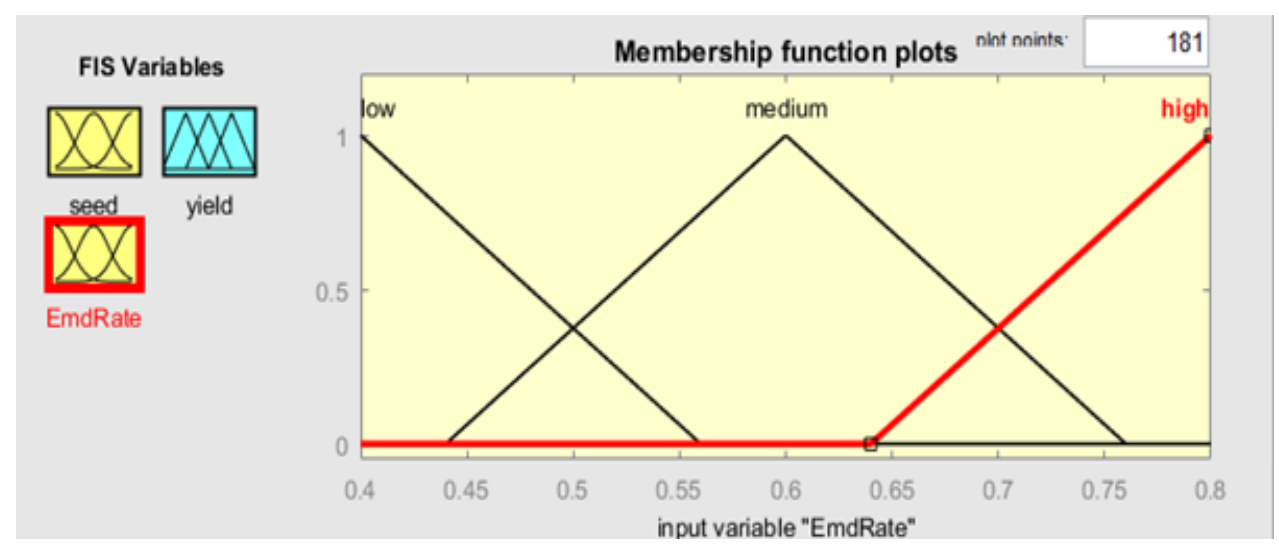

Figure 5 Emd rate input parameter membership functions

Graphical display in Matlab environment for the output variable of wheat yield per decare is presented in Figure 6. With the help of the fuzzy rule base, rules are created with the IF (if) - THEN (Then) structure for the system to be designed. In order to understand the relationship between the determined membership functions, a fuzzy rule base has been created.

A large number of rules are created that make the relationship between input and output parameters easy to understand. While the amount of seed used here is directly proportional to the yield per decare, the yield per decare is inversely proportional to the Emd rate. In short, the higher the seed amount, the higher the yield is expected, while the higher the barn, the lower the yield. This logic was taken into account while creating the rule base. 
Fuzzy logic rules, details of which are given above and created based on the opinions of experts, are given in Table 2. The newly created 18 numbers of rules are transferred to the fuzzy logic screen as shown in Figure 7.

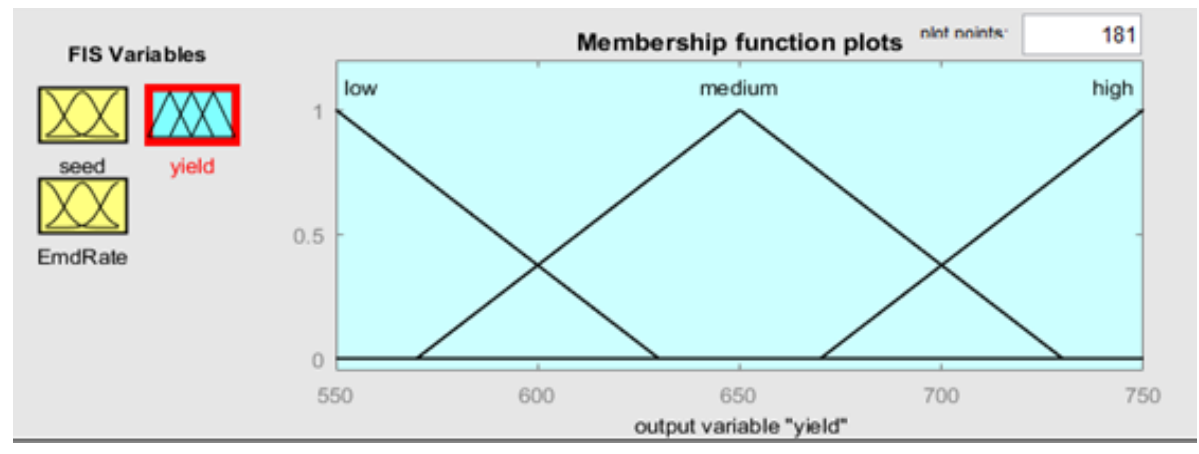

Figure 6 Membership functions of the output parameter of yield per decare

Table 2 Fuzzy logic rules

\begin{tabular}{|l|l|}
\hline 1. & If (seed is low) and (Emd Rate is low) then (yield is medium) \\
\hline 2. & If (seed is low) and (Emd Rate is medium) then (yield is medium) \\
\hline 3. & If (seed is low) and (Emd Rate is high) then (yield is low) \\
\hline 4. & If (seed is medium) and (Emd Rate is high) then (yield is low) \\
\hline 5. & If (seed is medium) and (Emd Rate is high) then (yield is medium) \\
\hline 6. & If (seed is medium) and (Emd Rate is medium) then (yield is medium) \\
\hline 7. & If (seed is medium) and (Emd Rate is low) then (yield is medium) \\
\hline 8. & If (seed is high) and (Emd Rate is low) then (yield is high) \\
\hline 9. & If (seed is low) and (Emd Rate is medium) then (yield is medium) \\
\hline 10. & If (seed is high) and (Emd Rate is high) then (yield is medium) \\
\hline 11. & If (seed is medium) and (Emd Rate is medium) then (yield is medium) \\
\hline 12. & If (seed is medium) and (Emd Rate is low) then (yield is medium) \\
\hline 13. & If (seed is high) and (Emd Rate is low) then (yield is medium) \\
\hline 14. & If (seed is low) and (Emd Rate is high) then (yield is low) \\
\hline 15. & If (seed is low) and (Emd Rate is medium) then (yield is low) \\
\hline 16. & If (seed is low) and (Emd Rate is medium) then (yield is medium) \\
\hline 17. & If (seed is low) and (Emd Rate is low) then (yield is medium) \\
\hline 18. & If (seed is medium) and (Emd Rate is low) then (yield is medium) \\
\hline
\end{tabular}




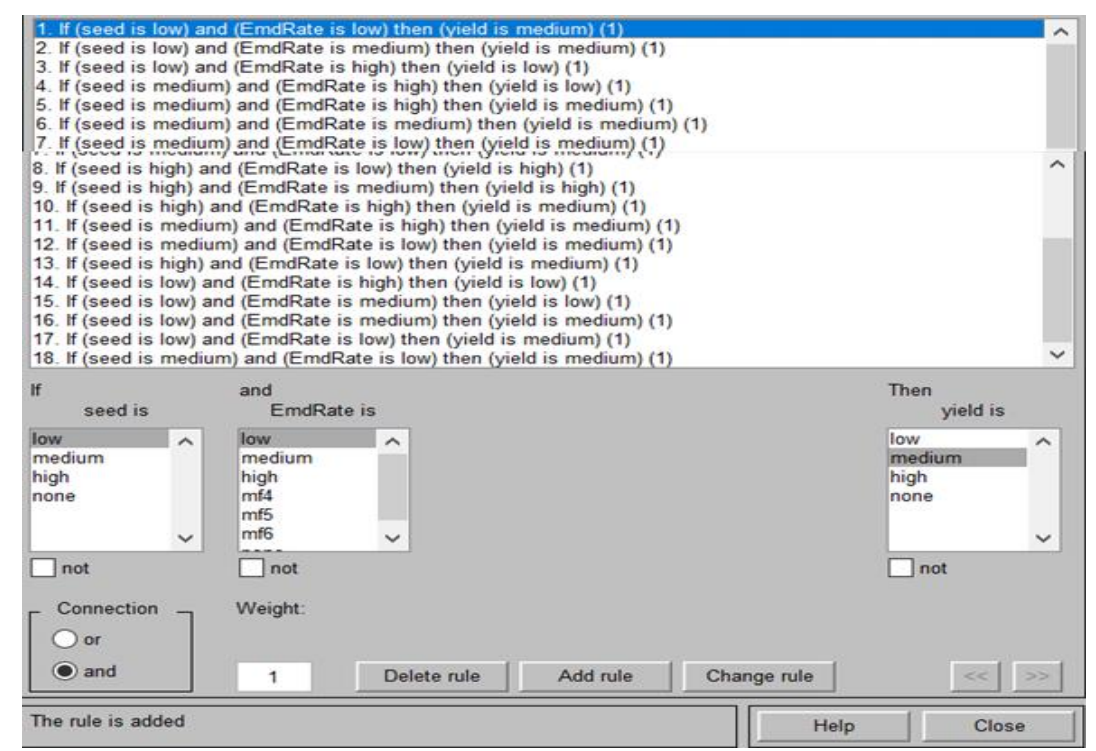

Figure 7 A view (screenshot) of fuzzy rules in MATLAB

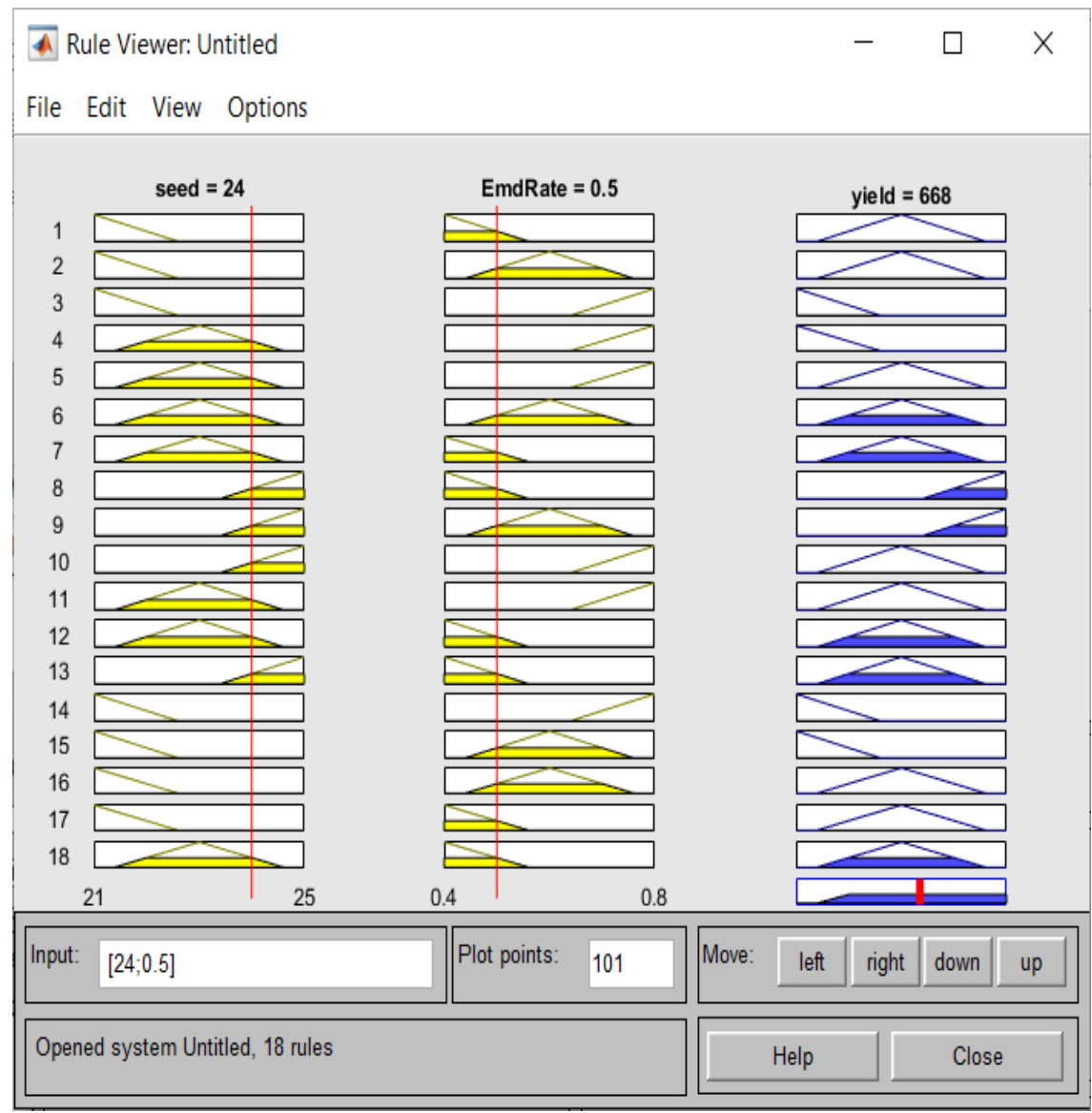

Figure 8 the defuzzification screen for the decision-making process of the model

The image of the decision-making process in determining the yield per decare with the fuzzy logic approach in MATLAB R2016b program is given in Figure 8. As seen in Figure 8, it is possible to determine the yield per decare, which is the output variable, by taking into account the seed and the rate of seed, which is one of the input variables. Here, when the seed amount is $24 \mathrm{~kg}$ and the Emd rate (\%) is 0.5, the wheat yield per decare in the wetland will be $668 \mathrm{~kg}$. Wheat yield can be estimated by giving various values for seed and Emd rate variables. According to this rule base, the wheat yield information per decare estimated by giving different values for seed and impregnation ratio is given in Table 3. 
Table 3 The estimated wheat yield based on input variables

\begin{tabular}{|c|c|c|}
\hline Seed (kg) & Emd rate (\%) & Yield (kg) \\
\hline 21 & 0.8 & 576 \\
\hline 21 & 0.75 & 593 \\
\hline 21 & 0.4 & 650 \\
\hline 21 & 0.5 & 632 \\
\hline 21.9 & 0.61 & 631 \\
\hline 22 & 0.75 & 632 \\
\hline 22.3 & 0.52 & 653 \\
\hline 23 & 0.64 & 650 \\
\hline 23 & 0.44 & 672 \\
\hline 23.5 & 0.5 & 653 \\
\hline 23.5 & 0.6 & 652 \\
\hline 23.6 & 0.62 & 653 \\
\hline 24 & 0.75 & 635 \\
\hline 24 & 0.4 & 668 \\
\hline 24.3 & 0.41 & 670 \\
\hline 24.5 & 0.4 & 671 \\
\hline 25 & 0.4 & 673 \\
\hline
\end{tabular}

As can be seen in Table 3, it is expected that the wheat yield per decare will increase as the amount of seed used increases and the Emd rate decreases. The effect of input variables on output variables according to the fuzzy rule base is given in Figure 9.

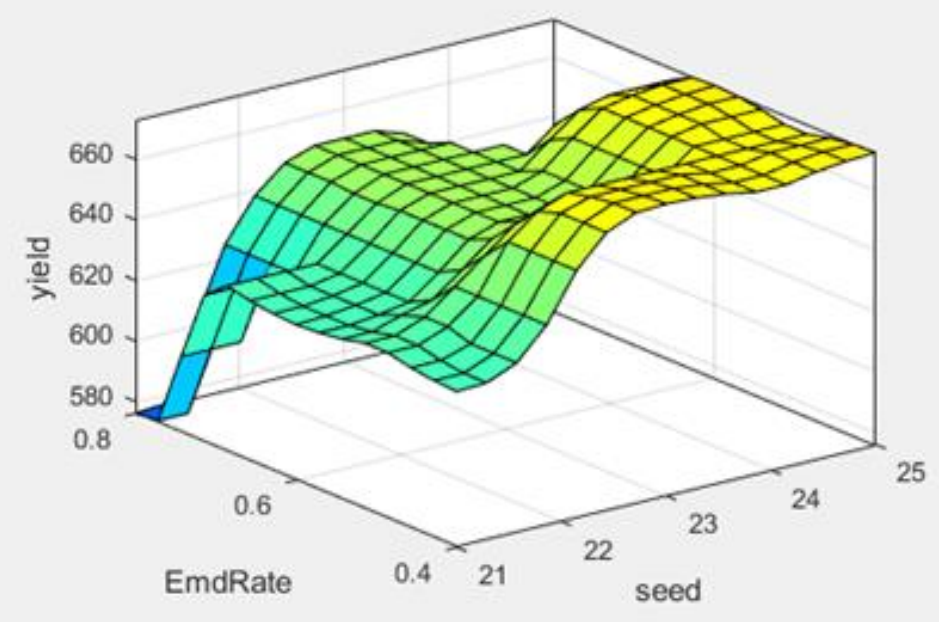

Figure 9 The effect of the exit of input variables to the rule base

When Figure 9 is examined, it is clearly seen that wheat yield increases as the seed value increases and the Emd rate decreases. 


\section{Conclusion}

In this study, the modelling has been made by using fuzzy logic to determine the wheat yield per decare by using the information on the amount of seed used and the Emd rate in the fields. In the modelling, while seed and Emd rate were used as input variables, the yield was used as output variable. In order to understand the relationship between input and output variables, a fuzzy rule base has been created. Mamdani type was used as the mechanism of deduction. The centroid method was used for clarification. The system is modelled in the MATLAB program.

In the study, a model was created to determine the wheat yield of farmers with fuzzy logic. When the seed amount used by the farmers per decare is $21 \mathrm{~kg}$ and the Emd rate is 0.8 , the minimum wheat yield was determined as $576 \mathrm{~kg}$. When the amount of wheat used is $25 \mathrm{~kg}$ and the Emd rate is 0.4 , the maximum wheat yield was determined as $673 \mathrm{~kg}$.

It has been revealed that the fuzzy logic model can give good results in estimating the yield per decare under conditions where plant pests are intense, within the possibilities of farmers.

In the periods when there is no fight against yeast in wheat, the yield decreases while the Emd rate increases. It has been determined that sunn is very damaging to cereal crops. Especially in the fight against pests in plant protection, it is possible to reduce and control the density of the sunflower population with effective implementation of protective measures, the cultural struggle and biological control. Effective and continuous release of natural enemies in the reduction and control of the sunflower density and in particular the parasitoid Trissolcus spp. By applying the species in the foreground in this business, it is aimed to keep the density of the pest around $1 \%$ and to contribute to the producer and the country's economy. In the fight against sunn, it will be ensured that the ecological balance is maintained and natural resources are prevented from being damaged within this framework.

\section{Compliance with ethical standards}

\section{Acknowledgments}

We would like to thank Batman Provincial Directorate of Agriculture for their support for the information used in this study.

\section{Disclosure of conflict of interest}

M. İlçin and Ş. Çelik declare that they have no competing interests.

\section{References}

[1] FAO [2018]. Food and Agriculture Organization of the United Nations. http://www.fao.org/faostat/en/\#data/QC

[2] (Accessed to: 15.09.2019).

[3] Lodos N. [1986]. Türkiye Entomolojisi II Genel, Uygulamalı ve Faunistik (II. Basım). Ege Üniversitesi, Ziraat Fakültesi Yayınları. (429):580.

[4] Özkan M and Babaroğlu NE. [2015]. Süne. Gıda ve Kontrol Genel Müdürlüğü Yayınları, Ses Reklam İletişim ve Basım Hizmetleri, Ankara, $208 \mathrm{~s}$.

[5] Memişoğlu H. [1985]. Ankara İlinde Süne Türlerinin (Eurygaster spp.)(Hemiptera: Pentatomidae) Yayılışları ve E. maura L.'nin Biyo-Ekolojisi ile Savaş Yöntemleri Üzerinde Araştırmalar. 194 s. Yayınlanmamış doktora tezi.

[6] Anonymous. [2017]. Batman İl Tarım Müdürlüğü, 2011-2017 Brifingi, Batman. 2017: 72.

[7] Chen G, Pham TT and Boustany NM. [2001]. Introduction to fuzzy sets, fuzzy logic, and fuzzy control systems. Appl. Mech., 54(6):B102-B103.

[8] Zadeh LA. [1965]. Information and control. Fuzzy sets., 8(3):338-53.

[9] Baykal N and Beyan T. [2004]. Bulanık mantık: uzman sistemler ve denetleyiciler. Bıçaklar Kitabevi. 